\title{
Efetividades do Programa Bolsa Verde no Assentamento Canudos em Goiás: uma análise da segurança alimentar e da preservação ambiental ${ }^{1}$
}

\author{
Effectivities Bolsa Verde Program in Settlement Straws in Goiás: an analysis of \\ food security and environmental preservation
}

\section{Effectivités Programme Bolsa Verde en Straws établissement dans Goiás: une analyse de la sécurité alimentaire et préservation de l'environnement}

\section{Efectividades del Programa Bolsa Verde en emplazamiento Canudos en Goiás: un análisis de la seguridad alimentaria y conservación del medio ambiente}

\author{
Monyele Camargo Graciano² \\ Klaus de Oliveira Abdala² \\ Leandro de Lima Santos ${ }^{3}$ \\ Luiz Manoel de Moraes Camargo Almeida ${ }^{3}$
}

\begin{abstract}
Recebido em 29/09/2016; revisado e aprovado em 12/06/2017; aceito em 12/06/2017
DOI: http://dx.doi.org/10.20435/inter.v19i1.1403
\end{abstract}

\begin{abstract}
Resumo: Este trabalho perfez uma análise do Programa Bolsa Verde a partir dos seus eixos institucionais: a conservação ambiental, a promoção da cidadania, a inclusão produtiva, a erradicação da pobreza rural, fazendo um alinhamento ao conceito de segurança alimentar e preservação ambiental a partir de indicadores específicos obtidos na experiência do Assentamento Canudos no Estado de Goiás.
\end{abstract}

Palavras-chave: Programa Bolsa Verde; segurança alimentar; preservação ambiental.

Abstract: This research amounted an analysis of the Bolsa Verde Program from its institutional axles: environmental conservation, promotion of citizenship a productive inclusion, the eradication of rural poverty, making hum alignment the food safety concept and environmental preservation indicators from specific obtained in Canudos settlement experience's State of Goiás.

Keywords: Bolsa Verde Program; food security; environmental protection.

Résumé: Cette recherché est élevé Une analyse du programme Bolsa Verde de son Essieux institutionnel: Protection de l'environnement, la promotion de la citoyenneté une inclusion productive, l'éradication de la pauvreté rurale, Faire Alignement hum les indicateurs Concept de la sécurité alimentaire et de préservation de l'environnement à partir de spécifique obtenu dans l'État de Canudos règlement Expérience de Goiás .

Mots-clés: Programme Bolsa Verde; la securite alimentaire; preservation de l'environnement.

Resumen: Este trabajo ha ascendido Un análisis del programa Bolsa Verde su Ejes Institucional : Conservación del ambiente, promoción de la ciudadanía una inclusión productiva, la erradicación de la pobreza rural , haciendo que los ajustes zumbido El concepto de Seguridad Alimentaria y la preservación del medio ambiente Indicadores De obtuvieron específica en asentamiento el estado de Canudos de Experiencia de Goiás.

Palabras clave: Programa Bolsa Verde; seguridad alimentaria; preservación del medio ambiente.

\footnotetext{
${ }_{1}^{1}$ Pesquisa desenvolvida para a Dissertação de Mestrado produzida junto ao Programa de Pós-Graduação em Agronegócio da Universidade Federal de Goiás, com apoio financeiro do Conselho Nacional de Desenvolvimento Científico e Tecnológico (CNPq).

${ }^{2}$ Universidade Federal de Goiás (UFG), Goiânia, Goiás, Brasil.

${ }^{3}$ Universidade Federal de São Carlos (UFSCar), São Carlos, São Paulo, Brasil.
} 


\section{INTRODUÇÃO}

O problema da preservação ambiental num contexto de desenvolvimento ${ }^{4}$ econômico gera debates conflitantes à medida que o crescimento das sociedades e a expansão das práticas agropecuárias se tornam os principais agentes de degradação da natureza. No Brasil, há diversos debates sobre o tema, sendo apontados como principais fatores degradantes o modelo produtivo agroindustrial, o aumento da população, o intenso processo de urbanização, a eminente exploração e supressão dos recursos naturais e a pobreza rural.

Segundo dados da Pesquisa Nacional por Amostra de Domicílio (PNAD), realizada em 2012, viviam em situação de pobreza extrema 9,2\% da população rural, e outros $23,8 \%$ encontravam-se na linha da pobreza, ou seja, viviam com uma renda per capita de $\mathrm{R} \$ 140,00$.

Conforme levantamento do Instituto Brasileiro de Geografia e Estatística (IBGE), os biomas brasileiros sofreram a supressão de grande parte de suas áreas de florestas para o avanço da lavoura e da criação agropecuária. A Mata Atlântica, até o ano de 2010, perdeu 88\% de sua área total para o desmatamento. Já o bioma Cerrado teve $49 \%$ de sua área desmatada até o mesmo ano. A Caatinga, até o ano de 2009, perdeu $54 \%$ de sua área. No bioma Amazônia, a área total desmatada se aproxima de $20 \%$ da área de floresta original e $15 \%$ da área que corresponde à Amazônia Legal ${ }^{5}$ (IBGE, 2012).

Nesse quadro, o principal desafio do Estado brasileiro é a promoção de políticas públicas formuladas sob o paradigma do desenvolvimento sustentável, ou seja, crescimento econômico com justiça social e conservação do meio-ambiente. O debate sobre a conservação ambiental alcançou notoriedade nas últimas décadas. O modelo produtivo exportador brasileiro empregado desde o período colonial não tinha essa preocupação em seus longos anos de apogeu. Hoje, o governo tem usado diversos instrumentos para favorecer métodos produtivos agrícolas que conservem o meio-ambiente.

Uma dessas ações é o Programa de Apoio à Conservação Ambiental - Bolsa Verde, instituído pelo Ministério do Meio Ambiente (MMA) em 2011. O programa tem, como principais objetivos, o incentivo à conservação dos ecossistemas, a promoção da cidadania, a melhoria nas condições de vida dos beneficiários, o aumento da renda para grupos familiares que estejam vivendo em situação de extrema pobreza no meio rural e, ainda que residam em áreas determinadas como prioritárias para a proteção ambiental, que estejam desenvolvendo atividades sustentáveis em suas propriedades. Além dessas proposições, o Bolsa Verde busca estimular a participação dos beneficiários em oficinas de capacitação ambiental, educacional, técnica, profissional, voltada para a educação ambiental e a inclusão produtiva (BRASIL, 2015a; 2015b).

Desse modo, uma política de desenvolvimento rural deve ser concebida a partir da sua natureza multissetorial, o que significa alinhar características econômicas, sociais e ambientais com o intento de promover a criação e/ou a manutenção de uma agricultura competitiva, a proteção e conservação do meio ambiente e a melhoria das condições de vida e renda das populações residentes em áreas rurais (VAN DEPOELE, 2000). O Programa Bolsa Verde pretende atingir todos esses objetivos.

\footnotetext{
${ }^{4} \mathrm{O}$ conceito de desenvolvimento deve ter como pressuposto o crescimento econômico associado a uma melhoria nos indicadores de bem-estar social, ambiental e econômico (VASCONCELLOS; GARCIA, 1998).

${ }^{5}$ A Amazônia Legal é composta pelos estados de Rondônia, Acre, Amazonas, Roraima, Pará, Amapá, Tocantins, Maranhão e Mato Grosso e corresponde à junção dos biomas Amazônia e parte do Cerrado (LEMOS; SILVA, 2011).
} 
O Programa de Apoio à Conservação Ambiental - Programa Bolsa Verde, foi instituído em 2011 pela Lei n. 12.512/2011 (BRASIL, 2011a) e regulamentado pelo Decreto n. 7.572/2011 (BRASIL, 2011b). O Programa Bolsa Verde é coordenado e operacionalizado pelo Ministério do Meio Ambiente (MMA), gerido pelo Comitê Gestor, com participação dos Ministérios do Desenvolvimento Social (MDS), do Desenvolvimento Agrário (MDA), dentre outros.

O Bolsa Verde contempla, atualmente, 73.083 beneficiários $^{6}$. Desses, 43.115 pessoas são beneficiadas pela cooperação entre o MMA e o INCRA; 23.970 são beneficiadas pela parceria entre o MMA e o Instituto Chico Mendes de Conservação da Biodiversidade (ICMBio); e 5.998 são beneficiadas pela colaboração da Secretaria do Patrimônio da União (SPU) e do MMA (BRASIL, 2015a; 2015b).

Os beneficiários do Programa Bolsa Verde devem promover o desenvolvimento sustentável dos recursos naturais existentes em suas propriedades, os quais devem estar contidos em áreas prioritárias de proteção, ter a inscrição no Cadastro Único do Governo Federal, ademais de ter renda familiar per capita não superior a $\mathrm{R} \$ 77,00$, ou seja, estar em situação de pobreza extrema. Assim, contemplados todos os requisitos já elencados, será feito, em contrapartida, pelo governo, o pagamento de $\mathrm{R} \$ 300,00$, repassados aos beneficiários trimestralmente, pelo prazo de dois anos, passíveis de prorrogação. Esse valor é uma forma de pagamento por serviços ambientais desenvolvidos pelos assentados ou por populações tradicionais rurais.

Atualmente, o Programa Bolsa Verde encontra-se inserido em todas as regiões brasileiras, mas o estado com maior número de beneficiários é o Pará, com 43.964 pessoas. Em Goiás, o programa contempla 954 beneficiários ${ }^{7}$, sendo 947 assentados da reforma agrária e sete inseridos em parceria com o ICMBio. Apesar de haver um considerável número de beneficiários, o Bolsa Verde ainda não conta com estudos ou avaliações de sua efetividade nesse Estado. A proposta deste trabalho foi preencher essa lacuna, pois um processo avaliativo se mostra de extrema importância para a correção de eventuais problemas de gestão que podem influenciar na efetividade do programa.

O universo empírico pesquisado foi o Assentamento Canudos, criado em 17 de março de 2000, conta com 329 famílias assentadas, sendo 74 delas beneficiadas pelo Bolsa Verde. É a maior experiência do programa no estado de Goiás em número de beneficiários. Desde sua criação, o Assentamento Canudos possuía uma vocação ambiental importante para toda mesorregião do Sul Goiano. Diante desse cenário, justificou-se a inserção do programa Bolsa Verde no universo empírico pesquisado; em razão disso este trabalho realizou-se uma análise da efetividade do programa no Projeto de Assentamento Sustentável Canudos em seus elementos institucionais centrais.

\section{METODOLOGIA}

Esta pesquisa, inciou-se pelo levantamento bibligráfico sobre política pública, desenvolvimento rural e sustentável, segurança alimentar e o Programa Bolsa Verde. Posteriormente, foi realizada a pesquisa documental em relatórios fornecidos pelo Ministério do Meio Ambiente (MMA) e pelo Instituto Nacional de Colonização e Reforma Agrária (INCRA), que possibilitaram a determinação do universo empírico a ser pesquisado, o Assentamento Canudos.

\footnotetext{
${ }^{6}$ Segundo dados disponibilizados no site do MMA em 5 de agosto de 2015.

${ }^{7}$ Conforme dados disponibilizados no Ministério do Meio Ambiente em 17/06/2015 (BRASIL, 2015a).
} 
Na pesquisa de campo realizou-se a coleta de dados por meio de entrevista, em que foram aplicados formulários ${ }^{8}$ semiestruturados. Outra técnica utilizada na coleta de dados foi o diário de campo, que, para Whitaker (2002), é um instrumento que aumenta a percepção do pesquisador em relação à realidade estudada, visto que se torna necessário tecer um registro sobre as observações percebidas.

Com o objetivo de determinar uma amostra significativa de indivíduos entrevistados, realizou-se o cálculo amostral, tendo uma população de 74 beneficiados, o nível de confiança de $90 \%$ e a margem de erro amostral de 10\%, assim verificou-se que a amostra necessária seria 36 beneficiados. Entretanto foi possível aplicar o formulário com 38 beneficiários do programa Bolsa Verde.

Para mensurar a efetividade do Programa Bolsa Verde quanto à conservação ambiental, foi utilizado o IA, desenvolvido por Barreto, Khan e Lima (2005), na Universidade Federal do Ceará, a partir de pesquisas realizadas em assentamentos rurais. O objetivo do IA é diagnosticar o viés de conservação ambiental junto aos beneficiários da reforma agrária.

Tal índice é auferido a partir da aplicação de um formulário, com dez perguntas, aos beneficiários do programa. Nesse formulário, serão ponderadas informações que indiquem a presença de práticas sustentáveis nas propriedades rurais, tais como controle de pragas, formas de conservação ambiental, maneiras de utilização do solo e outras.

\begin{tabular}{|c|l|}
\hline 1 & $\begin{array}{l}\text { Qual o método de controle de pragas utilizado na unidade produtiva? } \\
\text { (0) Agrotóxico (1) Nenhum método ou Biológico }\end{array}$ \\
\hline 2 & $\begin{array}{l}\text { Faz utilização de fogo nas atividades agropecuárias? } \\
\text { (0) Sim e (1) Não }\end{array}$ \\
\hline 3 & $\begin{array}{l}\text { Faz plantio de árvores para fins de conservação de solos? } \\
\text { (0) Não e (1) Sim }\end{array}$ \\
\hline 4 & $\begin{array}{l}\text { Existe área de reserva de mata nativa na propriedade? } \\
\text { (0) Não e (1) Sim }\end{array}$ \\
\hline 6 & $\begin{array}{l}\text { Utiliza prática de plantio para evitar a degradação do solo? } \\
\text { (0) Não e (1) Sim }\end{array}$ \\
\hline 7 & $\begin{array}{l}\text { A casa possui sistema de esgoto ou algum tipo de fossa? } \\
\text { (0) Não e (1) Sim } \\
\text { (0) Não e (1) Sim }\end{array}$ \\
\hline 8 & $\begin{array}{l}\text { Se necessário, faz calagem? } \\
\text { (0) Não e (1) Sim }\end{array}$ \\
\hline 9 & $\begin{array}{l}\text { Usa esterco animal? } \\
\text { (0) Não e (1) Sim }\end{array}$ \\
\hline 10 & $\begin{array}{l}\text { Utiliza o solo de acordo com a sua vocação? } \\
\text { (0) Não e (1) Sim }\end{array}$ \\
\hline
\end{tabular}

Quadro 1 - Formulário para aferição do IA

Fonte: Barreto, Khan e Lima (2005), adaptado pelos autores.

${ }^{8}$ O formulário aplicado nesta pesquisa encontra-se no apêndice deste trabalho. 
Tal instrumental é resultado de uma pesquisa realizada em assentamentos, na qual são contempladas outras categorias de análise para além da questão ambiental. Entretanto, nesta pesquisa, será empregada somente a formulação utilizada para a obtenção do índice ambiental. Há de se salientar que, em relação àquela pesquisa, esse índice passou por adaptação para ser aplicado e interpretado a partir de domicílios rurais em vez de comunidades. Nesse caso, as respostas percebem um padrão binário e recebem valores 0 ou 1, sendo somados os resultados para o alcance do IA.

A seguir, a relação das variáveis utilizadas no modelo, com seus respectivos pesos, para a aferição do IA.

\begin{tabular}{|l|l|}
\hline Baixo nível do indicador ambiental & $0<\mid \mathrm{A} \leq 5$ \\
\hline Médio nível do indicador ambiental & $5<\mid \mathrm{A} \leq 8$ \\
\hline Alto nível do indicador ambiental & $8<\mid \mathrm{A} \leq 10$ \\
\hline
\end{tabular}

Quadro 2 - Pontuação para classificação do IA por domicílio

Fonte: Adaptado de Barreto, Khan e Lima (2005).

Ao obter o IA em cada unidade familiar pesquisada, será conduzida uma análise interpretativa sobre os patamares encontrados. Essa etapa da pesquisa confrontará as informações obtidas em campo a partir do questionário, e elas poderão servir de parâmetro explicativo aos Índices Ambientais encontrados, tais como a existência de cursos de capacitação aos agricultores, a disseminação cultural de práticas sustentáveis, a assistência técnica, a diversificação produtiva, a pluriatividade, as condições de trabalho, a escolaridade dos agricultores, dentre outros.

Outro objetivo importante no Bolsa Verde é a erradicação da pobreza extrema. Para mensurar a efetividade do programa no tocante a esse objetivo será utilizada uma escala conhecida como Escala Brasileira de Segurança Alimentar (EBIA), que consiste em um formulário de questões semiestruturadas, que possibilita aferir o nível de (In)Segurança Alimentar das famílias beneficiadas. Essa escala é resultado de pesquisas da "Rede Alimenta", grupo de pesquisa da Faculdade de Ciências Médicas da Universidade Estadual de Campinas (UNICAMP), e é resultado de uma adaptação, ao cenário brasileiro, de um índice similar utilizado pelo Departamento de Agricultura dos Estados Unidos,

Atualmente, a utilização da EBIA é um procedimento amplamente difundido ao avaliar políticas públicas de segurança alimentar no Brasil, sendo contemplada pelo governo em pesquisas sobre situação alimentar em domicílios a partir da Pesquisa Nacional por Amostra de Domicílios (PNAD).

A EBIA é uma metodologia que possibilita a percepção do padrão alimentar dos domicílios e é um instrumento capaz de identificar diversos níveis de Insegurança Alimentar (IA), desde a preocupação com a privação alimentar no futuro, sobrevindo à restrição na qualidade da dieta, a limitação da qualidade e quantidade de alimentos consumidos, até a fome. O questionário é aplicado diretamente ao chefe do grupo familiar responsável pela alimentação do domicílio (SEGALL-CORRÊA, 2007). 


\begin{tabular}{|c|c|}
\hline 1 & $\begin{array}{l}\text { Nos últimos } 3 \text { meses, a(o) Sra.(Sr.) teve preocupação que a comida acabasse antes que pudesse } \\
\text { comprar mais comida? }\end{array}$ \\
\hline 2 & $\begin{array}{l}\text { Nos últimos } 3 \text { meses, a comida acabou antes que a(o) Sra. (Sr.) tivesse dinheiro para comprar } \\
\text { mais? }\end{array}$ \\
\hline 3 & $\begin{array}{l}\text { Nos últimos } 3 \text { meses, a(o) Sra.(Sr.) ficou sem dinheiro para ter uma alimentação saudável e } \\
\text { variada? }\end{array}$ \\
\hline 4 & $\begin{array}{l}\text { Nos últimos } 3 \text { meses, a(o) Sra.(Sr) teve que se arranjar com apenas alguns alimentos para sua(s) } \\
\text { criança(s)/adolescente(s), menores de } 18 \text { anos, porque o dinheiro acabou? }\end{array}$ \\
\hline 5 & $\begin{array}{l}\text { Nos últimos } 3 \text { meses, a(o) Sra.(Sr) não pode oferecer à(s) sua(s) criança(s)/adolescente(s), } \\
\text { menores de } 18 \text { anos, uma alimentação saudável e variada porque não tinha dinheiro? }\end{array}$ \\
\hline 6 & $\begin{array}{l}\text { Nos últimos } 3 \text { meses, a(s) criança(s) /adolescente(s), menores de } 18 \text { anos, não comeu } \\
\text { (comeram) quantidade suficiente porque não havia dinheiro suficiente para comprar comida? }\end{array}$ \\
\hline 7 & $\begin{array}{l}\text { Nos últimos } 3 \text { meses, a(o) Sra. (Sr.) ou algum adulto em sua casa diminuiu, alguma vez, a } \\
\text { quantidade de alimentos nas refeições ou pularam refeições, porque não havia dinheiro } \\
\text { suficiente para comprar a comida? }\end{array}$ \\
\hline 8 & $\begin{array}{l}\text { Nos últimos } 3 \text { meses, a(o) Sra.(Sr.) alguma vez comeu menos do que achou que devia porque } \\
\text { não havia dinheiro suficiente para comprar comida? }\end{array}$ \\
\hline 9 & $\begin{array}{l}\text { Nos últimos } 3 \text { meses, a(o) Sra.(Sr.) sentiu fome, mas não comeu, porque não tinha dinheiro } \\
\text { suficiente para comprar comida? }\end{array}$ \\
\hline 10 & $\begin{array}{l}\text { Nos últimos } 3 \text { meses, a(o) Sra. (Sr.) perdeu peso porque não tinha dinheiro suficiente para } \\
\text { comprar comida? }\end{array}$ \\
\hline 11 & $\begin{array}{l}\text { Nos últimos } 3 \text { meses, a(o) Sra.(Sr.) ou qualquer outro adulto em sua casa ficou, alguma vez, } \\
\text { um dia inteiro sem comer, ou teve apenas uma refeição ao dia, porque não havia dinheiro para } \\
\text { comprar a comida? }\end{array}$ \\
\hline 12 & $\begin{array}{l}\text { Nos últimos } 3 \text { meses, a (o) Sra.(Sr.) alguma vez diminuiu a quantidade de alimentos das refeições } \\
\text { de sua(s) criança(s)/adolescente(s) menores de } 18 \text { anos, porque não tinha dinheiro suficiente } \\
\text { para comprar a comida? }\end{array}$ \\
\hline 13 & $\begin{array}{l}\text { Nos últimos } 3 \text { meses, alguma(s) vez a(o) Sra.(Sr.) teve que deixar de fazer uma refeição da(s) } \\
\text { sua(s) criança(s)/adolescente(s), menores de } 18 \text { anos, porque não havia dinheiro para comprar } \\
\text { comida? }\end{array}$ \\
\hline 14 & $\begin{array}{l}\text { Nos últimos } 3 \text { meses, sua(s) criança(s)/adolescente(s), menores de } 18 \text { anos, teve(tiveram) fome, } \\
\text { mas a(o) Sra.(Sr.) simplesmente não podia comprar mais comida? }\end{array}$ \\
\hline 15 & $\begin{array}{l}\text { Nos últimos } 3 \text { meses, sua(s) criança(s)/adolescente(s), menores de } 18 \text { anos, ficou(ficaram) sem } \\
\text { comer por um dia inteiro porque não havia dinheiro para comprar a comida? }\end{array}$ \\
\hline
\end{tabular}

Quadro 3 - Escala Brasileira de Insegurança Alimentar (EBIA)

Fonte: IBGE (2013).

Para a obtenção do índice de (in)segurança alimentar, foram atribuídos pesos a cada resposta às questões. Tais pesos perfazem uma ordem binária, na qual uma resposta negativa terá o peso zero e uma resposta afirmativa peso 1 (um) e, ao final, são somados os valores referentes para todas as respostas. 


\begin{tabular}{|l|c|l|}
\hline \multicolumn{1}{|c|}{ CATEGORIA } & Pontuação* & \multicolumn{1}{|c|}{ Dimensão da (IN) Segurança Alimentar } \\
\hline Segurança Alimentar (SA) & 0 & $\begin{array}{l}\text { Acesso regular a alimentos de qualidade e em quantidade } \\
\text { suficiente, não há preocupação em restrição alimentar no } \\
\text { futuro. }\end{array}$ \\
\hline $\begin{array}{l}\text { Insegurança Alimentar } \\
\text { Leve (IA-leve) }\end{array}$ & $1-5$ & $\begin{array}{l}\text { Preocupação ou incerteza da disponibilidade de alimentos } \\
\text { em um futuro próximo, seja em quantidade, seja em } \\
\text { qualidade apropriada. }\end{array}$ \\
\hline $\begin{array}{l}\text { Insegurança Alimentar } \\
\text { Moderada (IA-moderada) }\end{array}$ & $6-10$ & $\begin{array}{l}\text { Diminuição na qualidade alimentar, visando manter a } \\
\text { quantidade de alimentos para adultos e crianças. }\end{array}$ \\
\hline $\begin{array}{l}\text { Insegurança Alimentar } \\
\text { Grave (IA-grave) }\end{array}$ & $11-15$ & $\begin{array}{l}\text { Diminuição quantitativa e qualitativa dos alimentos, e/ou } \\
\text { restrição nos padrões da alimentação, resultante da falta } \\
\text { de alimentos entre adultos e/ou crianças; e/ou privação de } \\
\text { alimentos; fome. }\end{array}$ \\
\hline
\end{tabular}

Quadro 4 - Níveis de (in)segurança alimentar da EBIA

OBS: *A classificação dos domicílios familiares sem menores de 18 anos terá a possibilidade de resposta até no máximo 9 pontos; Portanto, a pontuação poderá assumir os seguintes valores: SA - 0 ; IA-Leve - de 1 a 3; IA moderada de 4 a 6; e IA-Grave - 7 a 9.

Fonte: Sampaio et al. (2006.)

Para avaliar os efeitos do programa Bolsa Verde nos elementos de segurança alimentar bem como no IA, foram relacionados outras categorias de análise. Essas categorias contemplam fatores sociais, econômico e ambiental..

Quanto aos objetivos institucionais de promoção da cidadania e de capacitação ambiental, técnica e profissional, estes foram verificados a partir de questionamentos, que buscam averiguar as atividades que o governo vem articulando para que esses objetivos sejam alcançados.

\section{RESULTADO E DISCUSSÕES}

O universo empírico pesquisado neste trabalho foi o Assentamento "Canudos", inserido na microrregião do Vale do Rio dos Bois, localizado entre três municípios goiano: Campestre, Palmeiras e Guapó. A área total do Assentamento compreende mais de 12.000 .000 hectares (ha), conta com 329 famílias que possuem lotes de 18 a 20 ha. Foram entrevistados 38 beneficiários, ou seja, $52 \%$ das famílias beneficiadas no assentamento.

Dos entrevistados, 84\% foram do gênero feminino, a idade variou entre 21 a 62 anos Foi possível observar-se que, quanto à escolaridade dos beneficiários, existiam beneficiados alfabetizados até com ensino superior completo.

No tocante à moradia, $100 \%$ dos beneficiários do Programa Bolsa Verde residem em casas de alvenaria e têm energia elétrica. O abastecimento de água para 39\% é oriundo de cisterna e, para $61 \%$, de mini poço artesiano. Quanto ao afastamento sanitário, foi verificado que $92 \%$ dos beneficiários do programa enterram ou queimam o lixo no lote. Esse tipo de ação não é considerada uma prática sustentável para a conservação do solo, pois o descarte de resíduos sólidos sem tratamento e em locais inadequados pode ocasionar diversos danos ao meio ambiente, como contaminação da água, do solo e dos alimentos e, consequentemente, afetar a saúde humana (SILVA et al., 2014).

Verificou-se que as famílias, antes de sua integração ao Assentamento Canudos, viviam, em sua maioria (53\%), em outros municípios, porém na mesma região. Nos relatos, os municípios 
citados foram Goiânia, Aparecida de Goiânia e Turvânia. Há famílias que vieram de outras regiões do Estado que somam 34\% dos beneficiados. Detectou-se ainda que 13\% das famílias entrevistadas são de outros Estados brasileiros: Rondônia, Bahia, Pará e Tocantins. Um fator relevante é que não há, entre os beneficiários do Programa Bolsa Verde, assentados que já viviam em algum dos municípios que abrangem o Assentamento Canudos. Segundo Anacleto (2014), à época do acampamento houve ampla divulgação por parte da mídia das ações dos sem-terra, isso pode ter colaborado para o aumento de famílias que se integravam ao assentamento.

A renda agrícola das famílias beneficiárias corresponde ao valor declarado da comercialização dos produtos oriundos dos lotes. Considerando a especificidade da produção agrícola, que por vezes envolve sazonalidades e, consequentemente, oscilações de preços e quantidades, optou-se por categorizar renda estimada em frações de salário mínimo vigente. A moda, 50\%, é de beneficiários com renda agrícola entre 0,5 e 1 salário mínimo, seguida de $16 \%$ cujos rendimentos estão entre 1,5 e 2 salários mínimos. Nas extremidades, 13\% dos beneficiários afirmaram ter renda agrícola inferior a 0,5 salário mínimo e 5\% auferem mais de 3 salários mínimos ao mês através da comercialização dos seus produtos.

Quanto à renda total do grupo familiar. Nessa categoria, encontram-se comutadas todas as rendas auferidas pelo grupo familiar, ou seja, soma-se a renda agrícola, a remuneração por pluriatividade, que é o pagamento feito aos assentados por atividades realizadas fora dos lotes e ainda os valores dos auxílios financeiros, que englobam as pensões, aposentadorias, bem como os valores oriundos das políticas públicas que beneficiam o grupo familiar, como Programa Bolsa Família e o próprio Programa Bolsa Verde. A renda total mensal percebida pelo grupo familiar dos beneficiários tem moda de 31\% de beneficiários na faixa entre 1 e 1,5 salário mínimo, 24\% com rendimentos de 1,5 até 2 salários mínimos e outros 24\% informaram ter renda de 2 até 3 salários mínimos.

No que refere à diversificação produtiva, percebe-se que: $42 \%$ dos entrevistados estão produzindo somente uma cultura (agrícola ou pecuária); $29 \%$ estão se dedicando majoritariamente a duas culturas; $13 \%$ têm em seus lotes cinco ou mais culturas; $11 \%$ estão cultivando até quatro produtos distintos, e $5 \%$ não estão produzindo nenhuma cultura.

É importante salientar que, entre os que produzem em suas glebas, o principal item destinado à comercialização no Assentamento Canudos é o leite, produzido por $58 \%$ dos entrevistados. $13 \%$ cultivam mandioca; $11 \%$, frutas e os demais estão se dedicando à produção de aves, hortaliças e legumes. Quanto ao autoconsumo a moda das famílias entrevistadas, 52\%, produz mais que $25 \%$ e menos que $50 \%$ da sua própria dieta. $24 \%$ produzem até $25 \%$ dos produtos consumidos. $16 \%$ cultivam entre $50 \%$ a $75 \%$ dos alimentos. $8 \%$ não produzem nenhuma cultura para o autoconsumo. Não foi verificada nenhuma família que produzisse de $75 \%$ a $100 \%$ dos alimentos consumidos. Esses percentuais não foram deduzidos na renda total encontrada na análise dos resultados. 


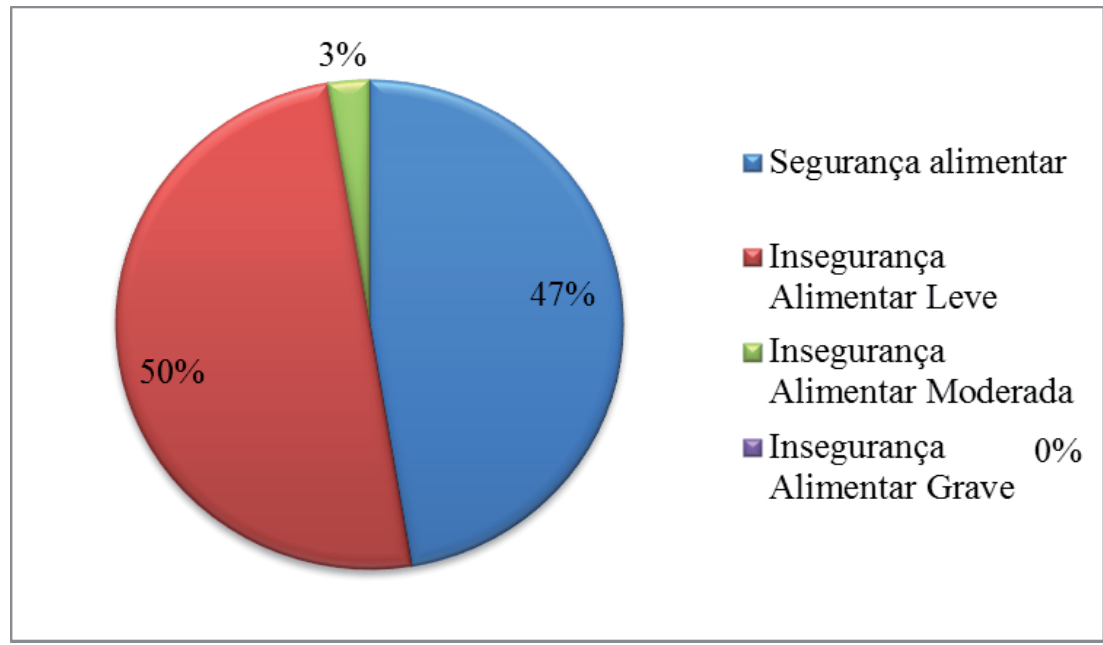

Gráfico 1 - Representação do grupo familiar conforme a EBIA Fonte: Pesquisa de Campo (2015).

Ao se analisar o Gráfico 1, nota-se que a maioria (50\%) dos beneficiários do Programa Bolsa Verde entrevistados no Assentamento Canudos encontra-se em níveis de Insegurança Alimentar Leve. São famílias que, nos últimos três meses, tinham se preocupado com a falta de algum alimento específico nas refeições, mas, em termos quantitativos, não existiu perda, situação reafirmada na fala de uma das beneficiárias, que diz: "Às vezes falta a mistura, mas sempre tem arroz, feijão e ovo". Outra parcela significativa, de $47 \%$ dos beneficiários, foi avaliada em situação de Segurança Alimentar, ou seja, não enfrentou nenhuma restrição alimentar, quantitativa ou qualitativa, nos últimos três meses. E ainda foi verificado que um beneficiário (3\%) teve diminuição na quantidade de alimentos consumidos nos últimos três meses. Entre os beneficiários do Programa Bolsa Verde no Assentamento Canudos, não foi diagnosticado nenhum grupo familiar que estivesse em níveis de Insegurança Alimentar Grave.

Para as análises a seguir, buscaram-se variáveis que poderiam apresentar relação com o nível de segurança alimentar das famílias, dada a abrangência do próprio conceito de segurança alimentar ampla, tais como escolaridade, renda agrícola, diversificação produtiva, autoconsumo, renda total e gasto com alimentação e, em última instância, a representatividade do benefício financeiro do Programa Bolsa Verde em relação aos dois últimos indicadores.

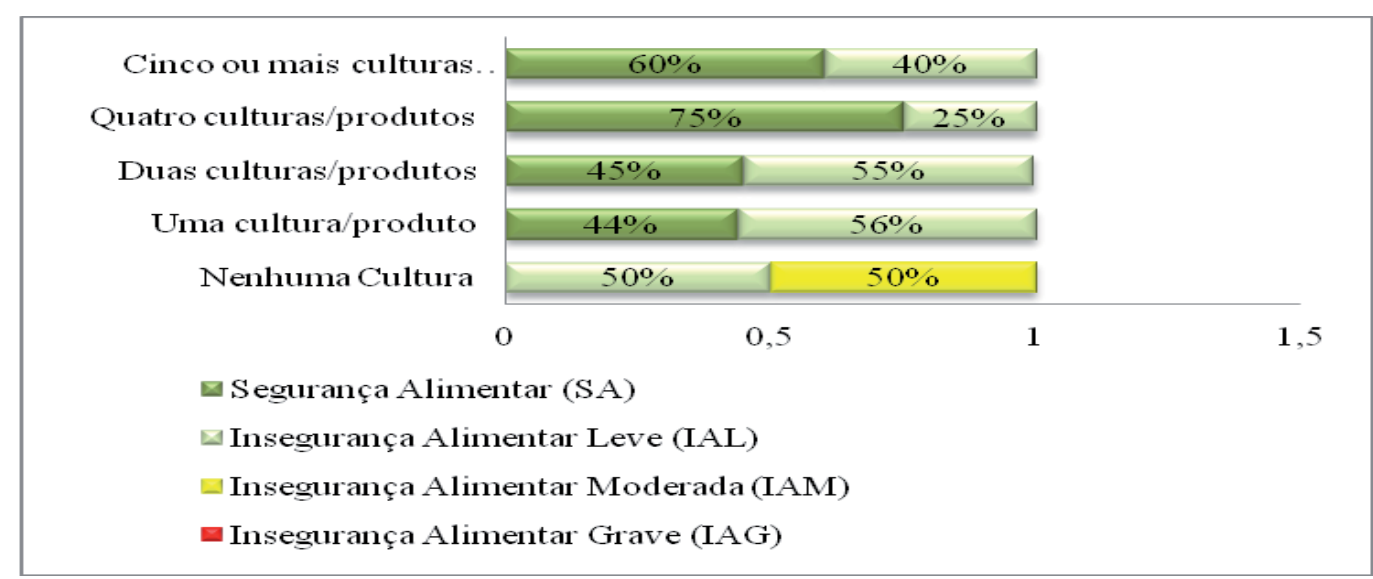

Gráfico 2 - Relação entre a diversificação produtiva e o nível de Insegurança Alimentar - EBIA Fonte: Pesquisa de Campo, 2015. 
O Gráfico 2 mostra que, quanto mais diversificada a produção, menores são os níveis de insegurança alimentar. Na coluna correspondente à categoria Nenhuma Cultura, os dados podem ser considerados outliers, pois contemplam apenas dois grupos familiares. Todavia, quando se analisam as demais colunas, é possível notar a tendência indicada, como na barra onde se encontra a classificação Uma Cultura: 44\% das famílias encontram-se em Segurança Alimentar, e 56\%, em Insegurança Alimentar Leve. Já na coluna acima, o nível de Segurança Alimentar apresenta-se maior e, consequentemente, a insegurança alimentar apresentou redução.

Os resultados sugerem que a diversificação produtiva para agricultores familiares é relevante, corroborando as conclusões de outras pesquisas, segundo as quais a produção de culturas diversificadas proporciona menor vulnerabilidade ante as adversidades temporais, maior oferta de produtos diversificados no mercado e elevação da renda, variedade para o autoconsumo e benefício aos níveis de segurança alimentar (FRANCHINI et al., 2011).

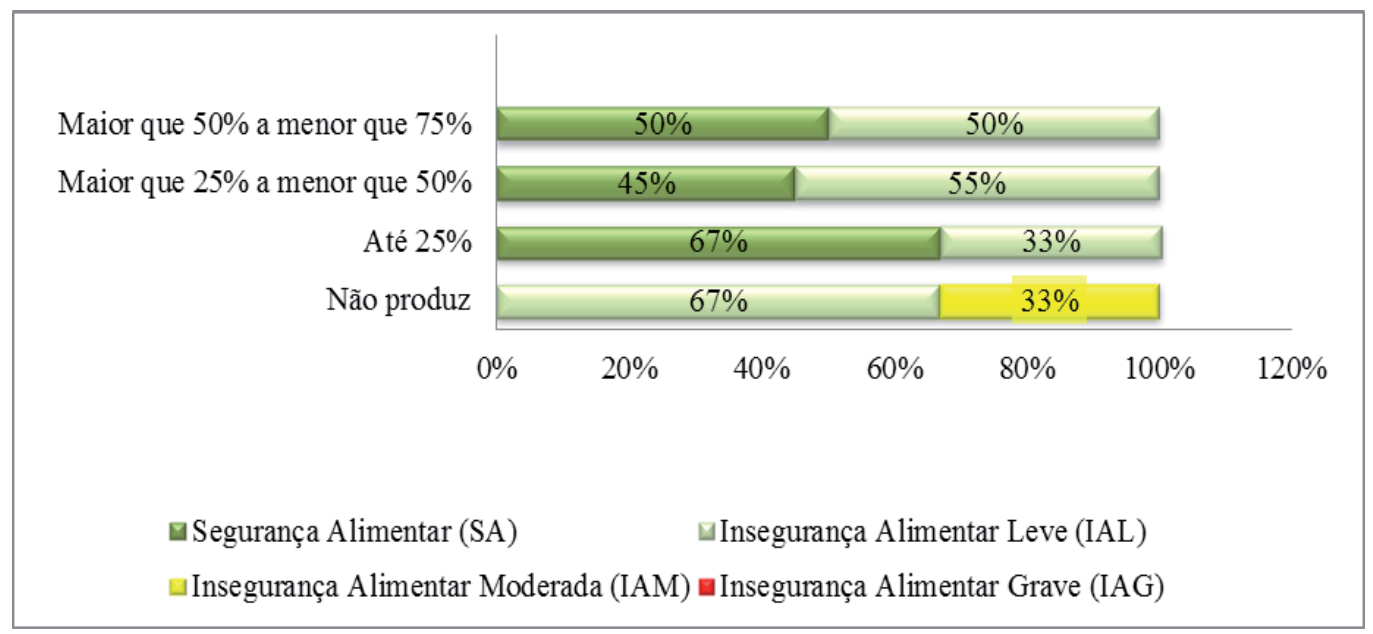

Gráfico 3- Relação do Autoconsumo com o nível de Insegurança Alimentar - EBIA Fonte: Pesquisa de Campo, 2015.

Ao se analisar os resultados presentes no Gráfico 3, nota-se uma tendência de diminuição dos níveis de Insegurança Alimentar conforme se eleva o percentual da produção destinada para o consumo familiar, o Autoconsumo. $67 \%$ das famílias entrevistadas que não estão produzindo nenhum tipo de cultura encontram-se em níveis de Insegurança Alimentar Leve, e 33\%, em Insegurança Alimentar Moderada. Entretanto famílias que produzem de $50 \%$ até $75 \%$ se encontram 50\% em Insegurança Alimentar Leve, e os outros 50\%, em nível de Segurança Alimentar, sugerindo relação com seu elevado autoconsumo. 


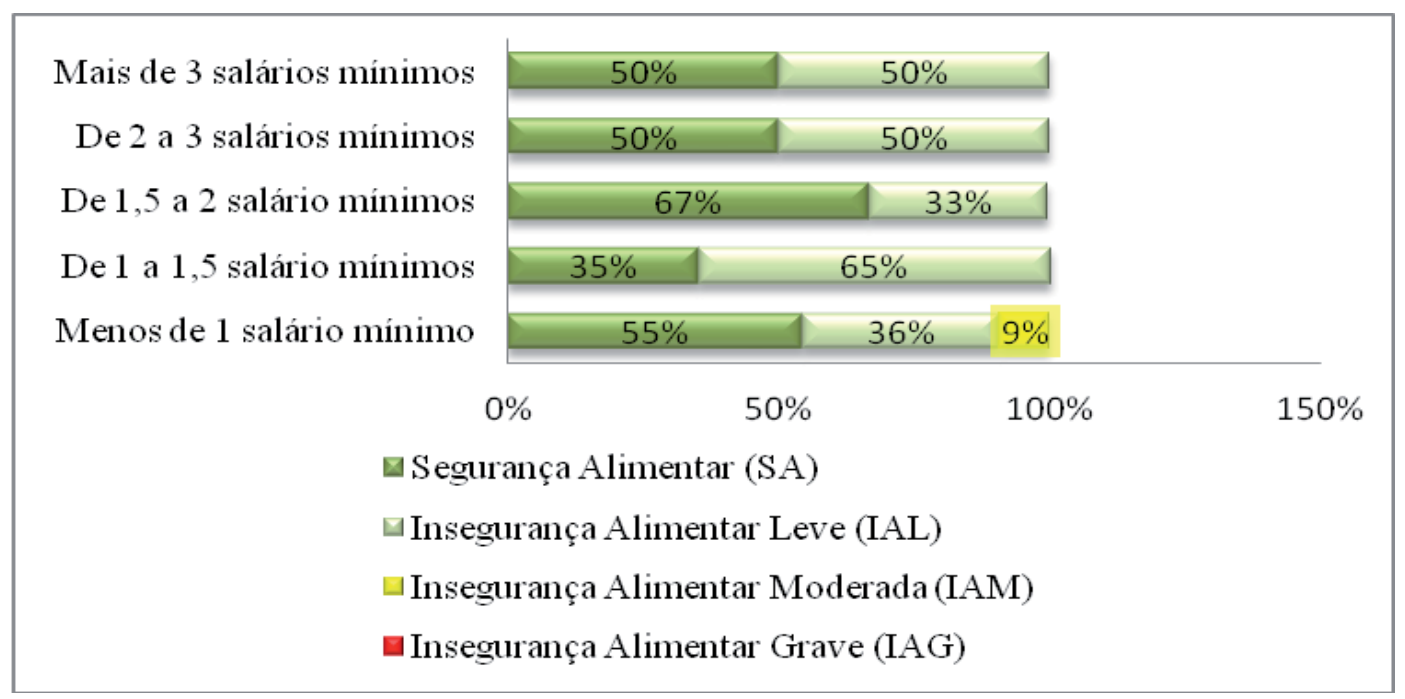

Gráfico 4- Relação entre a renda agrícola e o nível de Insegurança Alimentar - EBIA Fonte: Pesquisa de Campo, 2015.

O Gráfico 4 permite inferir que, quanto maior a renda agrícola, ou seja, a renda extraída do lote, menor o nível de Insegurança Alimentar. Na análise da categoria de beneficiários que possuem renda agrícola inferior a um salário mínimo, que qualitativamente se encontram em patamares mais preocupantes de Insegurança Alimentar por possuir percentuais moderados da EBIA (com exceção da segunda categoria, de 1 a 1,5 salário mínimo), os níveis de Segurança Alimentar tendem a crescer na média quanto maior for a renda agrícola.

Durante as entrevistas, uma das beneficiárias que não estava produzindo no lote, justificou dizendo que o chefe de família responsável pelas funções laborais estava com problemas de saúde e que eles ainda enfrentavam dificuldades com os recursos hídricos para a manutenção de uma lavoura, contando apenas com auxílios como o Bolsa Família e o Bolsa Verde para não serem atingidos por situação de Insegurança Alimentar mais severa.

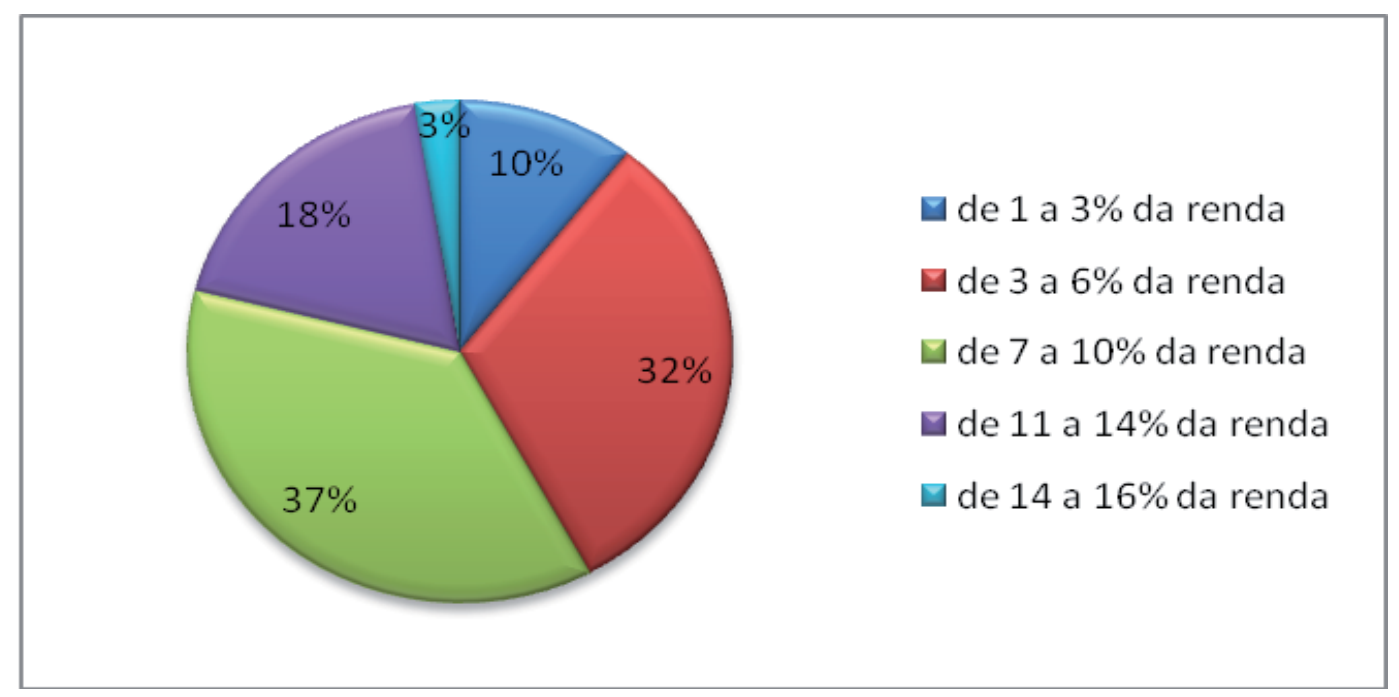

Gráfico 5 - Percentual do Bolsa Verde em relação à renda total mensal das famílias Fonte: Pesquisa de Campo, 2015. 
O valor pago aos beneficiários do Bolsa Verde corresponde a $\mathrm{R} \$ 300,00$ a cada três meses, portanto R\$100,00 por mês. Calculou-se sua proporção na renda total mensalmente percebida pelas famílias. Analisando o Gráfico 5, a moda é de $37 \%$ das famílias para as quais o Programa Bolsa Verde representa de $7 \%$ a $10 \%$ da renda total. Para 32\% a renda é complementada de 3\% a $6 \%$ pelo programa. Para $18 \%$, o valor corresponde de 11 a $14 \%$ da renda. A renda de $10 \%$ das famílias tem um complemento de 1 a 3\% pelo benefício pago e, para 3\% dos entrevistados, o valor corresponde de 14 a 16\% da renda total familiar. Esses números comprovam a efetividade do Bolsa Verde, sobretudo ao se considerar a importância da renda do programa na diminuição dos níveis de Insegurança Alimentar.

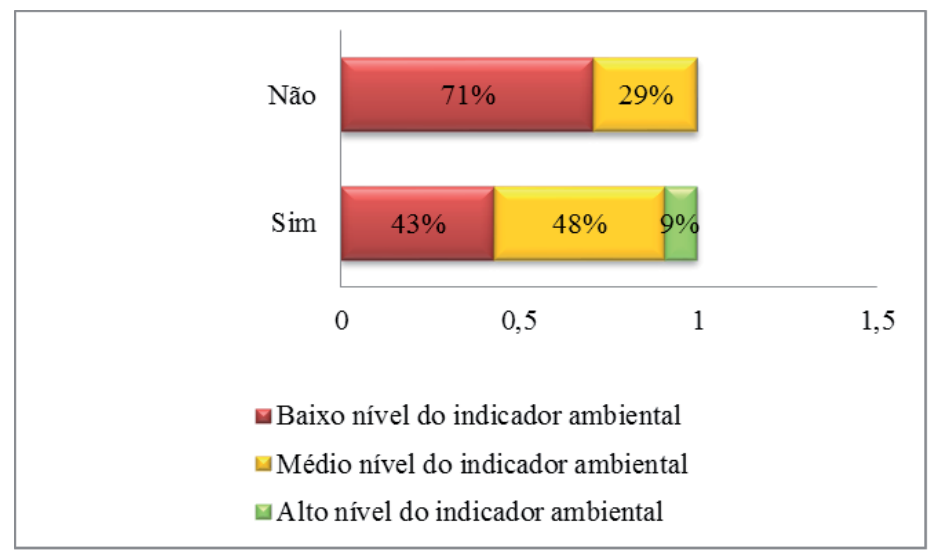

Gráfico 6 - Nível do IA dos lotes dos beneficiários Fonte: Pesquisa de Campo, 2015.

Ao analisar o Gráfico 6, percebe-se que na moda (55\%) os beneficiários do Assentamento Canudos apresentam um baixo nível do Indicador Ambiental. Em 42\% das glebas, foram detectados Médio IA e, em somente 3\%, percebeu-se um Alto IA. Em outras categorias de análise, detectou-se que, segundo $92 \%$ dos beneficiários do Bolsa Verde, não foi promovido no assentamento nenhum curso, oficina ou palestra destinada à educação ambiental desde a contratação do programa. Outro fator relevante para tais níveis de IA é que, de acordo com 97\% dos beneficiários, não houve nenhuma iniciativa governamental no auxílio ao desenvolvimento de práticas sustentáveis voltadas para as finalidades do Programa Bolsa Verde no Assentamento Canudos.

Com base nesses indícios, é possível questionar a efetividade do Programa Bolsa Verde quanto ao objetivo institucional de incentivar a conservação dos ecossistemas por meio da manutenção e uso sustentável, pois o IA é composto por questões em torno de práticas básicas para o desenvolvimento sustentável, as quais deveriam estar sendo multiplicadas pelos órgãos gestores no universo analisado. 


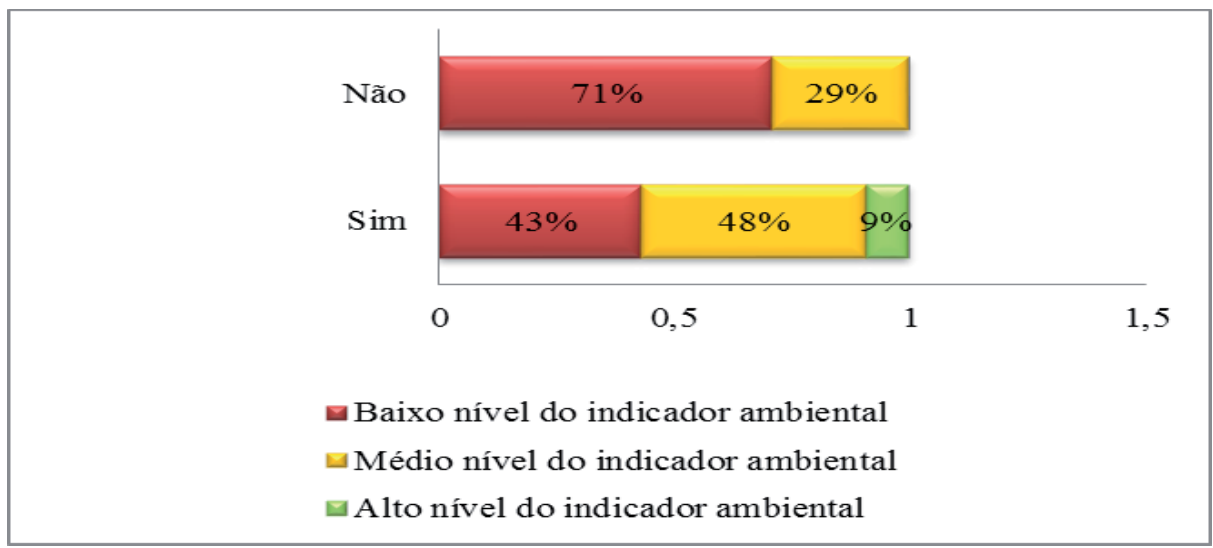

Gráfico 7 - Relação entre rotação de cultura e Indicador Ambiental Fonte: Pesquisa de Campo, 2015.

A rotação de cultura consiste na alternância de diferentes culturas, em determinado tempo, sob a mesma área e estação do ano (FRANCHINI et al., 2011). Observou-se que 71\% dos beneficiários que não fazem rotação de cultura encontram-se com baixo IA, e outros 29\%, em nível médio. Entre os beneficiários que promovem a rotação de cultivos em seus lotes: $48 \%$ mostram IA Médio; 43\%, Baixo IA; e 9\%, IA Alto.

A prática da rotação de culturas proporciona o aumento na produtividade agrícola, meIhoria na qualidade física, química e biológica do solo e ainda promove a redução de pragas e doenças na lavoura (FRANCHINI et al., 2011). Desse modo, a rotação de cultura se torna uma prática relevante para a conservação do solo, bem como para a conservação de todo o ambiente.

Como se constatou que a maioria dos beneficiários do Bolsa Verde não promove rotação de cultura em seus lotes, quanto à finalidade de incentivar o uso sustentável dos recursos naturais, o programa apresenta indícios de inefetividade.

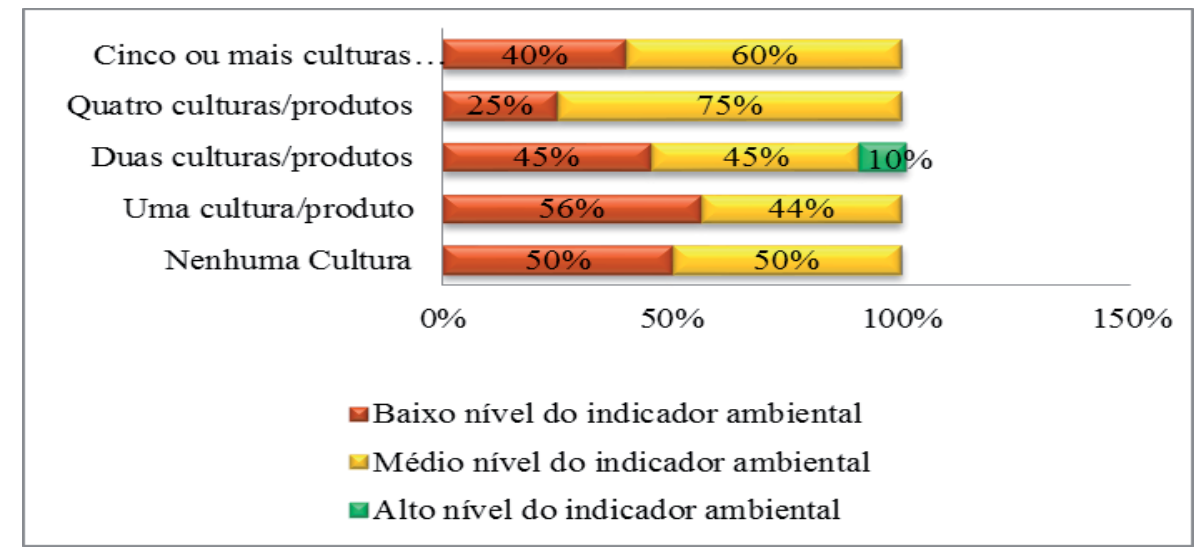

Gráfico 8 - Relação entre a diversificação produtiva e o Indicador Ambiental Fonte: Pesquisa de Campo, 2015.

O Gráfico 8 mostra uma tendência de correlação entre maior número de culturas e maior nível do Indicador Ambiental. A título de exemplo, dos beneficiários que estão produzindo quatro culturas, 75\% apresentam IA Médio. Existem duas exceções: uma se encontra no Alto Indicador Ambiental, representado somente por um grupo familiar, e a outra se refere aos beneficiários que não estão produzindo nenhuma cultura, somando somente dois grupos familiares. 
Para as famílias, a diversificação produtiva consiste em um fator importante para a renda, o autoconsumo e a segurança alimentar. Para a lavoura e o meio ambiente, pode significar menor vulnerabilidade às pragas, redução no uso de defensivos e a preservação do patrimônio genético, ou seja, da biodiversidade (WEID, 2009). Todavia, ainda que haja diversificação produtiva nos lotes, foi verificado um elevado percentual de uso de agrotóxico. 76\% dos agricultores utilizam defensivos agrícolas em suas lavouras. Segundo um entrevistado, "Eu uso sim, e agrotóxico pesado, pois o mais fraquinho não adianta nesse matagal aqui" (Entrevistado 3, pesquisa de campo 2015). Outro respondeu que "Estava ali, batendo um veneninho. Pode falar tudo, mas ninguém vai poder falar que minha roça morreu de praga" (Entrevistado 4, pesquisa de campo 2015).

O Programa Bolsa Verde não tem cumprido minimamente seu papel quanto à conscientização de seus beneficiários sobre o objetivo da manutenção e uso sustentável dos ecossistemas. Por outro lado, percebe-se insuficiente, ou inexistente, a devida fiscalização.

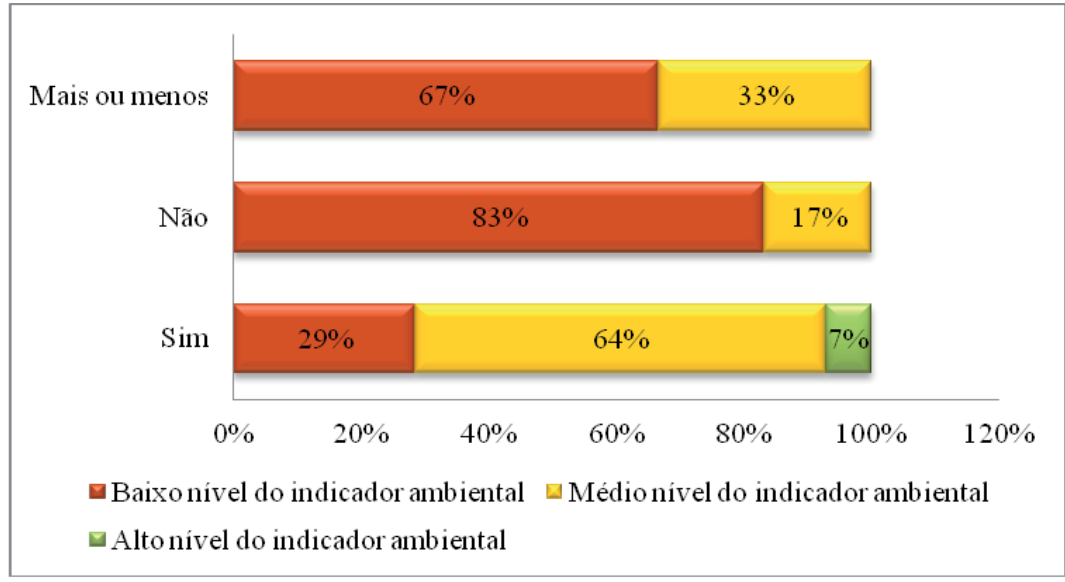

Gráfico 9 - Nível de compreensão dos beneficiários acerca do Programa Bolsa Verde Fonte: Pesquisa de Campo, 2015.

No Assentamento Canudos, segundo os relatos dos beneficiários, o Programa Bolsa Verde foi inserido a partir de 2012, quando participaram de uma reunião na qual foi apresentada uma relação de nomes de assentados que receberiam um valor trimestral de $\mathrm{R} \$ 300,00$, depositado em suas contas bancárias. De acordo com os beneficiários, não foi dito o critério de escolha das famílias comtempladas. Na reunião, eles tiveram que assinar alguns documentos e, conforme narrado por um assentado, "Eles explicaram que nós tínhamos que cuidar da reserva" (Entrevistado 2, pesquisa de campo, 2015).

No âmbito desta pesquisa, foram feitas questões aos beneficiários sobre seu conhecimento das finalidades do Programa Bolsa Verde. Como se pode observar no gráfico 9, 47\% dos entrevistados compreendem relativamente (mais ou menos) o seu propósito. Outros $37 \%$ assimilam em sua totalidade o programa, enquanto $16 \%$ dos beneficiários não entenderam o objetivo institucional do Programa Bolsa Verde. 


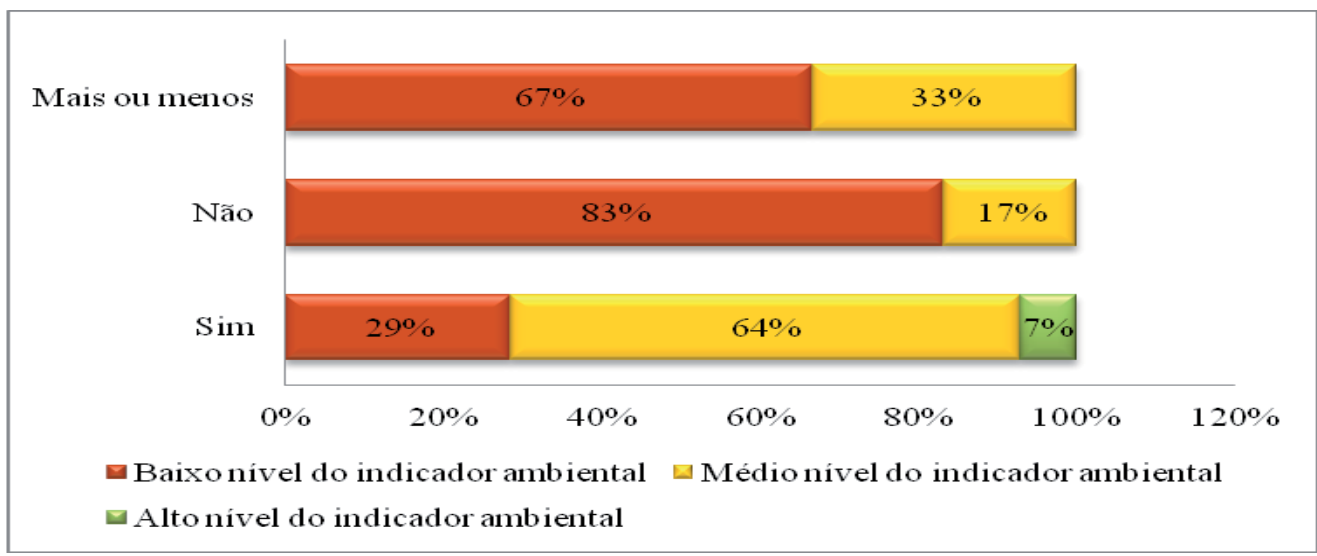

Gráfico 10 - Relação entre o nível de compreensão dos beneficiários e o Indicador Ambiental Fonte: Pesquisa de Campo, 2015.

No Gráfico 10, é possível perceber que, entre os beneficiários que não compreendem o programa, 83\% estão com Baixo Indicador Ambiental. Dos beneficiários que assimilam o programa relativamente (mais ou menos), 67\% mostram IA baixo, e 33\%, médio indicador. Entre aqueles que entenderam o programa em sua universalidade, 64\% estão em Médio Indicador Ambiental; $7 \%$, em Alto Indicador; e 29\%, em Baixo Indicador Ambiental.

Diante desses números, é possível afirmar que os resultados apontam para um entrave institucional no Programa Bolsa Verde em relação à transmissão de informações aos beneficiários, uma vez que a maioria deles não compreende a universalidade do programa e outros genericamente não o compreenderam. As práticas podem se modificar caso os agricultores tenham conhecimento de suas obrigações e direitos no programa. No momento da instituição de uma política pública, sob um dado ambiente, é necessário que haja comunicação entre os gestores e os contemplados pela política, que deve ter seus objetivos, finalidades e possíveis êxitos apresentados com clareza e eficiência aos sujeitos a que se destina.

\section{CONSIDERAÇÕES FINAIS}

Em termos conclusivos, o presente trabalho teceu um processo avaliatório do Programa Bolsa Verde, no Assentamento Canudos no Estado de Goiás, a partir de sua inserção em 2012. Buscou-se verificar o arranjo instrucional do programa, seus possíveis entraves, facilitadores e sua efetividade em relação aos eixos centrais da política: conservação ambiental, a promoção da cidadania, a inclusão produtiva, a erradicação da pobreza rural no universo empírico pesquisado.

Quanto à avaliação da efetividade do programa Bolsa Verde em relação ao objetivo institucional de erradicação da pobreza, este foi alinhado ao conceito de segurança alimentar e mensurado a partir da EBIA. Já no tocante ao objetivo de conservação ambiental, este foi auferido a partir do IA.

Após análise dos dados, percebeu-se que, em relação ao objetivo de erradicação da pobreza, este objetivo está sendo alcançado, uma vez que não foi detectado nenhum grupo familiar em situação de Insegurança Alimentar Grave, aqueles em condição de Insegurança Alimentar Moderada são uma pequena parcela da amostra, pois a maioria das famílias beneficiadas encontra-se em níveis de Insegurança Alimentar Leve e Segurança Alimentar. 
No tocante à contrapartida, no objetivo do programa de incentivar a conservação dos ecossistemas (manutenção e uso sustentável), verificou-se inefetividade. A análise dos dados do IA detectou que, em sua maioria, as famílias apresentam níveis baixo e médio, diagnóstico corroborado pelas demais categorias de análise, que também mostraram que os beneficiários não detêm conhecimento técnico das finalidades do Programa Bolsa Verde neste quesito.

As demais categorias de análise permitiram inferir que, em relação ao grau de escolaridade, tem-se a percepção de que há uma tendência de quanto maior a escolaridade menor é o nível de Insegurança Alimentar e melhor o nível do Indicador Ambiental. No tocante à renda, foi possível perceber que, em relação ao perfil alimentar, quanto maior a renda menor o nível de Insegurança Alimentar. Em relação ao autoconsumo, percebeu-se que quanto maior quantidade de alimentos destinados à dieta familiar menor o nível de Insegurança Alimentar e menor a dependência com o valor pago pelo programa em relação ao gasto com alimentação.

Isto posto, avaliando a efetividade do Programa Bolsa Verde em sua universalidade a partir dos resultados desta pesquisa, verificou-se que não houve a concretização de todos os seus objetivos institucionais. O programa, diante dos índices preocupantes do IA, aponta que, em relação à natureza preservacionista do Programa Bolsa Verde, esta não foi lhe atribuída em relação à realidade dos beneficiários, em contrapartida o programa referente aos níveis de insegurança alimentar detectados, assumiu meramente o caráter assistencialista de uma política pública de transferência de renda.

O Programa Bolsa Verde ainda é uma política pública relativamente nova e necessita de um processo avaliativo continuado. Esta pesquisa representa para a sociedade, para a administração pública e para a academia, um caminho para auxiliar outras pesquisas e monitorar o programa.

\section{REFERÊNCIAS}

ANACLETO, A. As disputas territoriais na construção do Assentamento Canudos, em Goiás. 2014. Dissertação (Mestrado em Geografia)- Faculdade de Ciências e Tecnologia da Universidade Estadual Paulista (UNESP), Presidente Prudente, SP, 2014.

BARRETO, R. C. S.; KHAN, A. S.; LIMA, P. V. P. Sustentabilidade dos assentamentos no Município de CaucaiaCE. Revista de Economia e Sociologia, Rio de Janeiro, v. 43, n. 2, p. 225-47, abr./jun. 2005.

BRASIL. Ministério do Meio Ambiente (MMA). Relatórios do Programa de Apoio à Conservação Ambiental Bolsa Verde. Brasília, DF, 2015a. Disponível em: <http://www.mma.gov.br/desenvolvimento-rural/bolsaverde/item/9141>. Acesso em: 24 ago. 2015.

. Ministério do Meio Ambiente (MMA). Programa de Apoio à Conservação Ambiental Bolsa Verde. Brasília, DF, 2015b. Disponível em: <http://www.mma.gov.br/desenvolvimento-rural/bolsa-verde>. Acesso em: 24 ago. 2015.

Lei 12.512, de 14 de outubro de 2011. Institui o Programa de Apoio à Conservação Ambiental e o Programa de Fomento às Atividades Produtivas Rurais; altera as Leis n. 10.696, de 2 de julho de 2003, 10.836, de 9 de janeiro de 2004, e 11.326, de 24 de julho de 2006. 2011a. Disponível em: <http://www. planalto.gov.br/ccivil_03/_ato2011-2014/2011/Lei/L12512.htm>. Acesso em: 25 jan. 2015.

Lei n. 7.572, de 28 de setembro de 2011. Institui o Programa de Apoio à Conservação Ambiental e o Programa de Fomento às Atividades Produtivas Rurais. 2011b. Disponível em: <http://www. planalto. gov.br/ccivil_03/_ato2011-2014/2011/Lei/L12512.htm>. Acesso em: 25 jan. 2015.

FRANCHINI, J. C.; COSTA, J. M. da; DEBIASI, H.; TORRES, E. Importância da rotação de culturas para a produção agrícola sustentável no Paraná. Londrina, PR: Embrapa Soja, 2011. 
INSTITUTO BRASILEIRO DE GEOGRAFIA E ESTATÍSTICA (IBGE). Pesquisa Nacional de Amostra de Domicílios (PNAD). Segurança Alimentar. Rio de Janeiro, 2013.

. Indicadores de Desenvolvimento Sustentável: Brasil 2012. Rio de Janeiro: IBGE, 2012. Disponível em: <https://biblioteca.ibge.gov.br/visualizacao/livros/liv59908.pdf>. Acesso em: 1o fev 2018.

LEMOS, A. L. F.; SILVA, J. A. Desmatamento na Amazônia Legal: evolução, causas, monitoramento e possibilidades de mitigação através do Fundo Amazônia. Floresta e Ambiente, v. 18, n. 1, p. 98-108, 2011.

SAMPAIO, M. de F. A. et al. (In)segurança alimentar: experiência de grupos focais com populações rurais do Estado de São Paulo. Segurança Alimentar e Nutricional, Campinas, SP, v. 13, n. 1, p. 64-77, 2006.

SEGALL-CORRÊA, A. M. Insegurança alimentar medida a partir da percepção de pessoas. Estudos Avançados, São Paulo, v. 21, n. 60, p. 143-54, maio/ago. 2007.

SILVA, R. A.; FÉLIX, K. K. F.; SOUZA, M. J. J. B.; SIQUEIRA, E. S. A gestão dos resíduos sólidos no meio rural: o estudo de um assentamento da Região Nordeste do Brasil. Gestão e Sociedade, Belo Horizone, v. 8, n. 20, p. 593-613, maio/ago. 2014.

VAN DEPOELE, L. The European Model of Agriculture (EMA): multifunctional agriculture and multisectoral rural development. In: INTERNATIONAL CONFERENCE EUROPEAN RURAL POLICY AT THE CROSSROADS, 2000. Conference Papers. Aberdeen, Scotland.

VASCONCELLOS, M. A.; GARCIA, M. E. Fundamentos de economia. São Paulo: Saraiva, 1998.

WEID, J. M. van der. Um novo lugar para a agricultura. In: PETERSEN, P. (Org.). Agricultura familiar camponesa na construção do futuro. Rio de Janeiro: AS-PTA, 2009.

WHITAKER, D. Sociologia rural: questões metodológicas emergentes. São Paulo: Letras à Margem, 2002.

\section{Sobre os autores:}

Monyele Camargo Graciano: Aluna do Mestrado em Agronegócio pela Universidade Federal de Goiás, inserida na linha de pesquisa Meio Ambiente e Desenvolvimento Regional. E-mail: monyelecamargo@gmail.com

Klaus de Oliveira Abdala: Docente na Universidade Federal de Goiás, nos cursos de Agronomia, Engenharia Florestal e no Mestrado em Agronegócio no Setor de Desenvolvimento Rural. E-mail: agroklaus@gmail.com

Leandro de Lima Santos: Professor da Universidade Federal de São Carlos (UFSCar), Doutor em Sociologia, área de concentração em Sociedade, Política e Cultura, e Mestre em Agronegócio pela Universidade Federal de Goiás (UFG). E-mail: leandrodelima@ufscar.br

Luiz Manoel de Moraes Camargo Almeida: Professor do Campus Lagoa do Sino da Universidade Federal de São Carlos (UFSCar) na área de Desenvolvimento Agroindustrial e Políticas Públicas. Pesquisador do Programa de Mestrado e Doutorado em Desenvolvimento Territorial e Políticas Públicas do Centro Universitário de Araraquara, SP. E-mail: manoel77@yahoo.com.br 
